TITLE:

\title{
Fighting with an unreliable weapon: opponent choice and risk avoidance in fiddler crab contests
}

AUTHOR(S):

Muramatsu, Daisuke; Koga, Tsunenori

\section{CITATION:}

Muramatsu, Daisuke ...[et al]. Fighting with an unreliable weapon: opponent choice and risk avoidance in fiddler crab contests. Behavioral Ecology and Sociobiology 2016, 70(5): 713-724

ISSUE DATE:

2016-05

URL:

http://hdl.handle.net/2433/217222

\section{RIGHT:}

The final publication is available at Springer via http://dx.doi.org/10.1007/s00265-016-2094-2; The full-text file will be made open to the public on 01 May 2017 in accordance with publisher's 'Terms and Conditions for Self-Archiving'.; $こ の$ 論文は出版社版でありません。引用の際には出版社版をご確認ご利用ください。; This is not the published version. Please cite only the published version. 
Names of the Authors:

Daisuke MURAMATSU and Tsunenori KOGA

\section{Title:}

Fighting with an unreliable weapon: opponent choice and risk avoidance in fiddler crab contests

The affiliations and addresses of the authors:

Daisuke MURAMATSU

Wildlife Research Center of Kyoto University, 2-24 Sekiden, Tanaka, Sakyo, Kyoto, 606-8203, Japan

Tsunenori KOGA

Faculty of Education, Wakayama University, 930 Sakaedani, Wakayama 640-8510, Japan

The e-mail address, telephone and fax numbers of the corresponding author: Daisuke MURAMATSU

E-mail address: muramatsu@wrc.kyoto-u.ac.jp

Telephone number: +81-75-771-4399

Fax number: +81-75-771-4394 


\begin{abstract}
Current signaling theories predict that animal signals are generally honest, but each signaling system allows some admixture of deception. Male fiddler crabs fight aggressively through use of their greatly enlarged major claw, which grows on the left or right side. Some males have fragile regenerated claws (regenerated males) and others have robust original claws (original males), but crabs cannot visually discriminate between the two types. In the present study, we conducted field observations in a population of Uca lactea to investigate how regenerated males fight with their inferior weapons, and how other males deal with the potential deception. Regenerated males employed bluffing tactics; they pretended to be aggressive to deter opponents, but surrendered when the fight escalated. Regenerated males tended to choose smaller and opposite-handed opponents, probably because claws can be grappled tightly in same-handed fights. The bluffing tactics seemed to be partially successful, because regenerated males were not selectively challenged by other males and defeated original males in $41.7 \%$ of the cases. However, original males developed counter-bluff tactics, such as choosing same-handed opponents and persisting in contests even when the opponent was larger. Consequently, original males defeated regenerated males equipped with a longer claw in $42.9 \%$ of the cases. In the most striking case, an original male evicted a resident male from his burrow despite the 42.7\% longer regenerated claw. This counter-bluff tactic decreases the reliance on the signal of strength (weapon size) and limits the benefit of bluffing.
\end{abstract}

\title{
Keywords:
}

Contest; Claw asymmetry; Bluff; Dishonesty; Weapon; Uca

\section{Significance statement:}

Male fiddler crabs (Uca lactea) fight with their major claw, which grows on either the left or right side. However, males with a fragile regenerated claw ("regenerated" males) which were similar in size to an original claw made deception in the fights. Regenerated males employed bluffing tactics; they behaved aggressively to deter opponents, but surrendered when the fight escalated. They chose smaller and opposite-handed opponents, because claws can be grappled tightly in same-handed fights. As a result, they defeated males with an original claw ("original" males) in $41.7 \%$ of the cases. Interestingly, however, original males developed a counter-bluff tactic: they chose same-handed opponents and persisted in contests even when the opponent was larger. Consequently, $42.9 \%$ of original males defeated regenerated males equipped with a larger claw. This counter-bluff tactic serves to "call the bluff" and limit the benefits of bluffing. 


\section{Introduction}

Animal signals must, on average, be reliable or honest to elicit the desired response from the receiver (Johnstone and Grafen 1993; Maynard Smith and Harper 2003; Stuart-Fox 2005). If the costs of responding to signals outweigh the benefits, the receivers should evolve to ignore the signals, and the signaling would then lose its effectiveness (Searcy and Nowicki 2005). Although there must be limits on how often deceptive signals can be used before they lose their effect (Maynard Smith and Harper 2003), each signaling system allows some admixture of deception as long as the signal response is adaptive on average (Semple and McComb 1996; Searcy and Nowicki 2005). Indeed, dishonest signaling is commonly seen in the animal world (e.g., Steger and Caldwell 1983; Adams and Caldwell 1990; Backwell et al. 2000; Candolin 2000; Elwood et al. 2006; Wilson et al. 2007; Munoz et al. 2008; Lailvaux et al. 2009; Walter et al. 2011; Angilletta and Wilson 2012).

In the context of agonistic interactions, weapons are commonly used to signal fighting ability and resource-holding potential (Searcy and Nowicki 2005; Bywater et al. 2008). Male fiddler crabs (Uca spp.) have one major claw and one minor claw, and the major claw occurs at equal frequency on the left and right sides of most species (Zeil et al. 2006; Backwell et al. 2007). The major claw is used for display and fighting (Rosenberg 2001; Pope 2005; Callander et al. 2013), and the size of this claw is an important indicator of a crab's fighting ability (Jennions and Backwell 1996; Jaroensutasinee and Jaroensutasinee 2003; Jaroensutasinee and Tantichodok 2003; Morrell et al. 2005). Males occasionally lose the major claw to predators or during an escalated contest, but they can regenerate their claw within a few months (Yamaguchi 1973). In some species, regenerated claws are less robust than the original ones, and thus becomes an inferior weapon for male-male fights (Backwell et al. 2000; Lailvaux et al. 2009; Bywater et al. 2014). However, neither males nor females can distinguish a regenerated claw from an original one (Reaney et al. 2008), and, as such, regenerated claws represent effective bluffing tools in male-male contests (Backwell et al. 2000). In the escalated stages of a fight, males interlock their major claws and try to fling their opponent. Males with regenerated claws may be inferior in such escalated contests, and may try to avoid claw-interlock. Claws can be grappled tightly when two contestants have their major claw on the same side, but it may be mechanically more challenging for opposite-handed contestants to interlock claws (ESM_1.mpg). Hyatt and Salmon (1978) reported that forceful claw contacts, such as claw interlacing, gripping, and flinging, are less frequent in fights between oppositehanded contestants (i.e., right-handed vs. left-handed). Therefore, same-handed fights are potentially more perilous for those involved, and regenerated males may avoid fighting with same-handed opponents.

In the present study, we investigated sequential opponent choice and fighting tactics in a wild population of Uca lactea, and investigated their tactics in terms of their choice of opponent and the subsequent fight. Specifically, we emphasized the tactical differences between males equipped with a regenerated major claw (hereafter, "regenerated males") and those with their original major claw (hereafter, "original males"). To clarify the interaction between males, we defined a "contest" as all agonistic interactions, including non-contact displays, and a "fight" as a contest in which direct physical contact occurs.

Regenerated males may primarily rely on bluffing tactics: they behave aggressively to deter their opponents, but surrender if the contest is likely to escalate. Regenerated males will preferentially choose a smaller opponent in order to repel them without engaging in fights. In addition, they will tend to evade same-handed 
fights to reduce the likelihood of a perilous claw-interlock that might result in loss of the fight or even of the claw. After careful consideration of their choice of opponent, regenerated males may occasionally engage in fights. A fight classically consists of three stages: the contact, interlock, and fling stages (Table 1). Fights usually proceed in this sequence. Any given fight may end at any of the three stages. Males would experience little or no risk of injury if the fight ends at the contact stage, but the risk of injury increases in the interlock and fling stages. Thus, regenerated males may surrender when fights escalate to the interlock stage, and they would rarely continue to the fling stage. We further investigated the outcome of the fights to determine how often and in what situations regenerated males would win a fight despite their more fragile weapon. We hypothesized that bluffing is more likely to be successful when the bluffer is larger than its opponent (Adams and Caldwell 1990); therefore, the disadvantage of having a regenerated claw can be compensated for by the possession of a major claw that is longer than that of the opponent.

Original males may use counter-bluff tactics: they try to maintain the contest even if the opponent appears larger, and behave as if they were aware that the opponent potentially has a regenerated claw. In reality, they cannot discriminate a regenerated claw from an original claw; therefore, they would not be able to choose to selectively fight against regenerated males. Instead, original males may selectively fight against same-handed opponents, because they would assume that their opponent potentially has a regenerated claw. By selecting same-handed opponents, original males may deter bluffing opponents, and thus reduce their time and energy investment in a contest, as well as their risk of predation.

Based on the above description, we hypothesized that: (1) the size of the regenerated claws (i.e., their length) should resemble that of original claws; (2) samehanded fights will be less frequent when one or both contestants have a regenerated claw but will occur more frequently when both contestants have their original claw; (3) regenerated males would tend to be larger in fights between original and regenerated males; (4) fights would tend not to escalate when one or both contestants have a regenerated claw; and (5) original males will often defeat larger regenerated males, but regenerated males will rarely defeat larger original males. Based on our observations, we discuss the efficacy of bluffing and counter-bluffing tactics in a wild population of $U$. lactea.

\section{Methods}

Our field observations were carried out in a dense colony of $U$. lactea on an intertidal mudflat in the estuary of the Waka River, Wakayama, Japan (34 $\left.19^{\prime} \mathrm{N}, 135^{\circ} 17^{\prime} \mathrm{E}\right)$. Crabs were active on the mudflat surface during diurnal low tides, except on days with heavy rain. Observations were carried out each day from ebb to flood tides between August and September 2011. We searched for naturally occurring male-male aggressive interactions by surveying approximately $20 \mathrm{~m}^{2}$ of the mudflat surface, and videotaped the fights whenever possible. It was not possible to record data blindly because our study involved focal animals in the field. Contestants were either classified as "resident" (i.e., had their own burrow) or "intruder" (lacking a burrow). Residents and intruders were easily discriminated by their behavior. Residents were found feeding or waving their claw around the burrow entrance, and rushed back to their own burrow in a straight line when frightened, whereas intruders wandered around the habitat, and surrounding residents performed rapid vertical waving toward intruder males that approached their burrow (see Muramatsu 2011a). After 
videotaping a contest, we captured both contestants by hand, using a 1-m-long wooden stick to block them from escaping into their burrow, as previously described (Muramatsu 2010a). We measured the carapace width and claw length (propodus length of the major claw) to the nearest $0.05 \mathrm{~mm}$ using calipers, and we recorded the side of the major claw (right or left), claw type (original or regenerated), and residency status (resident or intruder). Regenerated claws could be distinguished from original claws by the lack of teeth in the gape of the claw (Yamaguchi 1973; Reaney et al. 2008). We observed no fights in which a regenerated claw had clearly not regenerated to its original size. This suggests that crabs were unwilling to engage in a fight until their claw had completely regenerated. Crabs were marked by painting an ID number on their carapace for individual identification, and the paint was coated with cyanoacrylate adhesive to prevent abrasion. After retaining the crabs for 10 minutes in a plastic cup to allow the adhesive to solidify, residents were released into their own burrows and intruders were released on the mudflat surface.

We examined video footage of the male-male fights and recorded the details of the fights. For each fight, we recorded the combinations of claw type (original vs. regenerated), body side of the major claw (left vs. right), and residency (resident vs. intruder) of each contestant to test whether males make a biased choice of opponent when they engage in fights. Winners were defined as the males that remained at the fight site while the opponent left; losers were defined as males that left the fight site when the fight ended, and included males that walked away from the fight site and males that re-entered their burrow until their entire body disappeared from the mudflat surface. In some cases, both contestants left the fight site at the same time to escape a predator (such as the crab Helicana japonica) or to protect their burrows from other incoming crabs. In such cases, we excluded the data from our analysis.

\section{Statistical analyses}

We tested for significant differences in carapace widths and claw lengths between original and regenerated males using Student's $t$-test. We also examined the size difference between contestants in original vs. regenerated fighting pairs using paired $t$-tests to determine whether regenerated males tended to select smaller opponents.

We also tested for a correlation between carapace width and claw length as a function of the type of claw using a general linear model (GLM). Because the major claw length of the related species Uca pugilator increases almost isometrically with the square of the carapace width (the allometric constant, $a$, is 1.981; Pratt and McLain 2002), we included models that contain the square of carapace width in our analysis. Claw length was fitted as a response variable, and carapace width, claw type, the interaction between carapace width and claw type, the square of carapace width, and the interaction between claw type and the square of carapace width were fitted as explanatory variables. We calculated Akaike's information criterion (AIC) values for all possible models, and the model that yielded the smallest AIC value was selected as the best model.

The combinations of contestants in male-male fights were analyzed to reveal any significant tendency in the choice of opponent. The combinations of the contestants' claw type (original vs. original, original vs. regenerated, or regenerated vs. regenerated) and the expected values calculated from the number of observed original and regenerated males were compared using the $G$-test (a likelihood-ratio test). If regenerated males are challenged by other crabs more frequently than expected based on their proportion of the population, the observed combinations of contestants will differ significantly from the expected values. Similarly, we analyzed the combinations 
of contestants' residency (resident vs. resident, resident vs. intruder, or intruder vs. intruder) using the $G$-test. If the contestants competed only for burrows, contests between intruders would not occur (i.e., because both lack a burrow to defend), and thus the observed frequency of contests between intruders would be lower than if contests occurred for reasons such as the possession of a burrow. The combination of the contestants' handedness (same- or opposite-handed contests) in relation to the combination of claw types (both contestants had their original major claw, or at least one contestant had a regenerated claw) was analyzed using Fisher's exact test. This will reveal whether regenerated males avoid same-handed contests and whether original males prefer same-handed contests.

We compared the carapace widths in pairs of contestants at the contact, interlock, and fling stages using the Games-Howell test (Games and Howell 1976). Similarly, we analyzed the claw length differences between pairs of contestants at the contact, interlock, and fling stages using the Games-Howell test. We used this statistical method to account for the existence of heterogeneous variances.

To examine the effects of claw length, carapace width, claw type, residency, handedness, and fighting stage on the fight outcome, it is necessary to consider the status of both contestants. In the present study, we randomly assigned each crab in a contest to either the focal or opponent role. We performed this randomization to eliminate any bias in our selection of the focal male. We calculated claw length differences between paired contestants (by subtracting the claw length of the opponent from that of the focal male). Similarly, we determined the difference in carapace width between paired contestants (by subtracting the carapace width of the opponent from that of the focal male). Thus, claw length and carapace width differences were negative when the opponent male was larger than the focal male. To examine the magnitude of the disadvantage caused by possessing a regenerated claw on the outcome of the fight, we defined two categories: original-regenerated and regenerated-original, with the two words in each pair representing the claw type of the focal and opponent males, respectively. Other combinations of claw types (i.e., original-original and regenerated-regenerated) were treated as missing values in this analysis. Similarly, we configured four categories of fight (resident-resident, resident-intruder, intruder-resident, and intruder-intruder) to account for the combinations of residency.

The combination of contestants' handedness (same- or opposite-handed) may also affect the fight outcome. Therefore, to examine the effect of handedness in relation to the combination of claw types, we defined four categories (original-regeneratedsame, original-regenerated-opposite, regenerated-original-same, and regeneratedoriginal-opposite), with the three words in each category representing the claw type of the focal male, the claw type of the opponent male, and the combination of contestants' handedness, respectively. Similarly, we configured six categories (original-regenerated-contact, original-regenerated-interlock, original-regeneratedfling, regenerated-original-contact, regenerated-original-interlock, and regeneratedoriginal-fling) to examine the effects of fight escalation on the fight outcome. The three words in each category represent the claw type of the focal male, the claw type of the opponent male, and the stage reached in the contest, respectively.

The data were analyzed using the glmer function of the lme4 package (Generalized Linear Mixed-effects Models), implemented in the R statistical package (R Core Team 2015). The outcome of the fight (win or lose) was analyzed as a binary response variable, and the claw length difference, carapace width difference, combination of claw types, combination of residency, combination of handedness, and 
fighting stage were fitted as explanatory variables. Binomial errors and a logit link function were used to analyze the data. To account for inter-individual variation of focal and opponent males in the model, we used two random factors: the IDs of the focal and opponent males. We calculated AIC values for all combinations of explanatory variables, and the model that yielded the smallest AIC value was selected as the best model to predict the probability of winning. Because we expected claw length and carapace width to be strongly correlated, we excluded models that contained both of these factors to avoid autocorrelation.

\section{Results}

We recorded a total of 138 fights between 139 U. lactea male contestants. The contestants consisted of 110 males with original claws and 29 males with regenerated claws. Two original males had a chipped propodus, and because their claw length could not be measured accurately, the major claw lengths of these males were treated as missing values in our analyses.

\section{Carapace widths and claw lengths of original and regenerated males}

Regenerated males had a slightly larger carapace width and slightly larger major and minor claw lengths than the original males, but the difference was only marginally significant (Table 2).

We observed a total of 42 fights, excluding two duplicate cases (fights between the same pair), between original and regenerated males. Of these fights, the carapace width and major claw length of the regenerated males were both significantly greater than those of the original males (Table 3). Thus, regenerated males tended to fight against smaller opponents equipped with smaller weapons.

\section{Correlation between carapace width and claw length}

The model of claw length containing only carapace width as the explanatory variable was selected as the best model (Table 4). All other explanatory variables (claw type, interaction between carapace width and claw type, square of carapace width, and interaction between the square of carapace width and claw type) produced a weaker fit.

Figure 1 shows that claw length was significantly linearly related to carapace widths in both original and regenerated males (original male: $Y=2.407 X-11.774$, $R_{\text {adj }}^{2}=0.955, F_{1,106}=2268, P<0.001$; regenerated male: $Y=2.474 X-12.908, R^{2}{ }_{\text {adj }}=$ $\left.0.635, F_{1,27}=49.72, P<0.001\right)$. The original and regenerated males had similar regression lines, but regenerated males had a larger data dispersion than original males (Fig. 1).

\section{Claw type and residency status of the contestants}

A total of 122 fights, excluding 16 duplicate cases, were used in the following analyses. Fights of original vs. original males, original vs. regenerated males, and regenerated vs. regenerated males occurred in 79,42 , and 1 case(s), respectively. The expected values calculated from the number of observed original and regenerated males were 76.4, 40.3, and 5.3, respectively. There was no significant bias for the combinations of fighting pairs ( $G$-test; $G=3.3416, \mathrm{df}=2, P=0.188)$, thus, regenerated males were not selectively challenged by other males.

Fights of resident vs. resident, resident vs. intruder, and intruder vs. intruder occurred in 76, 45, and 1 case(s), respectively. The expected values were 69.6, 45.1, 
and 7.3, respectively. Fights between intruders were considerably less frequent than expected. However, the difference between the observed and expected frequencies was only marginally significant ( $G$-test; $G=5.772$, df $=2, P=0.056$ ).

The proportion of regenerated males was $19.0 \%(20 / 105)$ in resident males and $26.5 \%$ (9/34) in intruders when these males were captured for the first time. There was no significant difference in the proportions of regenerated males that were a resident or an intruder (Fisher's exact test; $P=0.344$ ). Thus, there was no evidence that original males tend to own a burrow.

\section{Combinations of contestants' handedness}

Fights between same-handed contestants and opposite-handed contestants were observed in 67 and 55 cases, respectively. The expected values calculated from the number of observed left- and right-handed males were 61.7 and 60.3 cases, respectively. There was no significant bias in the combination of fighting pairs $(G$ test; $G=0.4873$, df $=1, P=0.485$ ).

Of the fights taking place between original males, $63.3 \%(50 / 79)$ of them occurred between same-handed contestants (right vs. right or left vs. left). When at least one contestant had a regenerated claw, 39.5\% (17/43) of the fights occurred between same-handed contestants. The proportions of these two types of match-up differed significantly (Fisher's exact test; $P<0.05$ ). Thus, males with original claws tended to fight more with same-handed opponents, and males with regenerated claws tended to fight more with opposite-handed opponents.

\section{Fighting stages}

Clear fighting outcomes were obtained in 110 of 122 fights. The differences in carapace width between the contestants were larger for crabs that only reached the contact stage than in crabs that escalated to the interlock and fling stages (Fig. 2a). There were significant differences between carapace widths in the contact and interlock stages (Games-Howell test; $t=4.366, P<0.001$ ) and between the contact and fling stages $(t=2.888, P<0.05)$, but not between the interlock and fling stages $(t$ $=0.439, P=0.899)$. Similarly, the differences in claw length between two contestants were larger in the contact stage than in the interlock and fling stages (Fig. 2b). There were significant differences in claw length between the contact and interlock stages (Games-Howell test; $t=2.506, P<0.05)$ and between the contact and fling stages $(t$ $=2.929, P<0.05)$, but not between the interlock and fling stages $(t=0.380, P=$ 0.924).

Of the fights between original males, the numbers of fights that ended at the contact, interlock, and fling stages were 36, 20, and 17, respectively (Fig. 3). When one contestant had a regenerated claw, these numbers were 22,12 , and 2 , respectively. Contests that escalated to the fling stage were considerably fewer when one contestant had a regenerated claw, and the proportions of each stage of a fight differed marginally significantly from the proportions when neither contestant had a regenerated claw (Fisher's exact test; $P=0.068$ ). Thus, most of the regenerated males surrendered when the contest escalated to the interlock stage. In a typical example, a regenerated male tried to shake his claw loose when the opponent pinched the regenerated claw (ESM_2.mpg). In this case, a resident male with a 4.5-mm-longer regenerated claw surrendered his burrow to an intruder with an original claw. This example also showed that the original males tended to not surrender despite their opponent's much larger weapon.

Of the fights between resident males, the numbers of fights that ended at the 
contact, interlock, and fling stages were 41, 14, and 11, respectively (Fig. 4). Within the fights between a resident and an intruder, these numbers were 17, 18, and 8, respectively. The proportion of fights that ended at the contact stage was much larger for fights between resident males $(62.1 \%)$ than in fights between a resident and an intruder $(39.5 \%)$, whereas the proportion of fights that ended at the interlock stage was much smaller for fights between residents. The proportions of fight frequencies in each stage differed significantly between these two types of match-up (resident vs. resident and resident vs. intruder) (Fisher's exact test; $P<0.05$ ). Thus, fights between resident males tended to terminate earlier.

\section{Fight outcomes}

We analyzed the effects of carapace width and claw length on fight outcomes using the data from 110 fights that had a clear outcome. Carapace widths of winning and losing males were significantly positively linearly related (Fig. $5 ; Y=0.696 X+3.544$, $\left.R_{\text {adj }}^{2}=0.536, F_{1,108}=127, P<0.001\right)$, as were the claw lengths of winning and losing males (Fig. $6 ; Y=0.760 X+3.385, R^{2}$ adj $=0.546, F_{1,106}=129.8, P<0.001$ ). This suggests that males fought mostly against similar-sized opponents. Of these fights, $66.4 \%$ (73/110) of the winners had a wider carapace than their opponent (Fig. 5), and $75.0 \%$ (81/108) of the winners had a longer major claw than their opponent (Fig. 6), suggesting that larger males were more likely to win.

Of the fights won by males with smaller claws $(n=27)$, the largest difference in claw length observed between the two contestants was $7.35 \mathrm{~mm}$ : the winner had a 17.20-mm-long original claw, and the loser had a 24.55-mm-long regenerated claw. Thus, in this case, an original male defeated a regenerated opponent equipped with a $42.7 \%$ larger weapon. In this fight, both contestants were left-handed residents, and the loser (which had a regenerated claw) fled from the smaller opponent just before their claws interlocked (ESM_3.mpg).

Fights between original and regenerated males were observed 36 times. Original males won 21 of the fights $(58.3 \%)$, and $57.1 \%(12 / 21)$ of the winners had a longer claw. Regenerated males won 15 of the fights $(41.7 \%)$, and $86.7 \%(13 / 15)$ of the winners had a longer claw (i.e., all but two points in Fig. 6 were below the equality line). However, the difference between these proportions was only marginally significant (Fisher's exact test; $P=0.077$ ). The results indicate that regenerated males were often defeated by original males even when the regenerated male's claw was longer than that of its opponent, and they rarely won a contest when they had a smaller claw.

\section{Factors affecting the outcome of the fight}

Clear fighting outcomes were obtained in 125 of 138 fights. The same combinations of the contestants were observed on average 1.5 times (range 1-4) for focal males and 1.4 times (range 1-5) for opponent males. The glmer analysis for the probability of winning showed that claw length was the most important factor that determined the outcome of the fight, because all of the top 10 models contained "claw length difference" as an explanatory variable (Table 5). The best model contained two explanatory variables: "claw length difference" and "combination of claw types". There was a positive correlation between the probability of winning and the claw length difference, suggesting that focal males tended to win the fights when they had a longer claw than their opponent (Table 6). The best model also showed that the combination of claw types negatively affected the probability of winning when the focal male had a regenerated claw and the opponent male had an original claw (Table 
6). These results indicate that males with original claws tended to win the fights more often when their opponent had a regenerated claw.

The best model led to the calculation that regenerated males could beat original males in $29.1 \%$ of the size-matched contests, and that the probability of winning was $50.0 \%$ when they have a 2.13 -mm-longer claw, $58.9 \%$ when they have a 3 -mm-longer claw, and $68.5 \%$ when they have a 4-mm-longer claw (Fig. 7). When the focal male had an original major claw, it had a higher probability of winning the contest than for focal males with a regenerated major claw at all claw-length differences.

\section{Discussion}

\section{Bluff and counter-bluff tactics}

Dishonest signaling of strength is quite common in some species of insects (Steger and Caldwell 1983; Adams and Caldwell 1990) and crustaceans (Backwell et al. 2000; Lailvaux et al. 2009; Walter et al. 2011; Angilletta and Wilson 2012). Our data showed that more than $20 \%$ of males had regenerated claws, which are weaker than the originals, but strongly resemble the original claws in length. Crabs do not seem to be able to discriminate a regenerated claw from an original claw, because regenerated males were not selectively challenged by other males. Thus, high-frequency cheating appears to be successful in this wild population of $U$. lactea.

Interestingly, however, original males seemed to develop counter-bluff tactics, behaving as if they assumed that their opponent potentially had a regenerated claw. Original males selectively fought against same-handed opponents, making regenerated males surrender before the fight escalated. Furthermore, original males persisted in the contests even when the opponent had a longer major claw, and consequently defeated a regenerated opponent equipped with a longer claw in $42.9 \%$ of the cases. Viewed in this light, regenerated males failed to elicit the desired response from original males.

Our results showed that $U$. lactea males adapted their fighting tactics and choice of opponent depending on whether they had lost their major claw. There is growing evidence that animals switch their tactics during their lifetime; this is referred to as a "conditional strategy with alternative tactics" (e.g., Tsubaki and Ono 1986; Krupa 1989; Mills and Reynolds 2003; Shine et al. 2003; Luttbeg 2004; Sato et al. 2004; Goncalves et al. 2005; Raihani et al. 2008). In contrast, few animals employ inherently fixed strategies ("alternative strategies with genetic polymorphism among individuals"; Gross 1996). In the case of U. lactea, males switch their tactics when they lose and regenerate their major claw, but the tactics then become fixed after regeneration of the claw.

\section{Heterogeneity of contest costs and resource values among contestants}

Elwood and Arnott (2012) described two main factors from game theory that affect contests such as those between the crabs in our study: contest costs (e.g., fatigue, injury) and resource value (e.g., amount of food, quality of nest). The present results showed that both contest costs and resource values seemed to vary among the contestants.

We found that male-male fights in $U$. lactea advanced to the fling stage less frequently when one of the contestants had a regenerated claw. Similarly, fights in $U$. pugilator showed that males are less likely to escalate a fight when one or both contestants have a regenerated claw (McLain et al. 2010). These phenomena may be caused by differences between males in the perceived contest costs: the potential costs 
of escalated fights may differ between original and regenerated males because the weapon of regenerated males is weaker and more fragile. Thus, the motivation to maintain a contest may be lower in regenerated males, and they may give up more easily when the contest escalates.

In the present study, fighting pairs were roughly equal in size. Size-assortative fighting has also been described in Uca annulipes (Jennions and Backwell 1996) and in Uca mjoebergi (Morrell et al. 2005). These phenomena may be due to differences in the type of resource that is most valued by each contestant; that is, different types of contestants (e.g., different morphs or body sizes) compete for different resources (Bolton et al. 2013). For example, males of the sand goby (Pomatoschistus minutus) prefer a nest that is suitable for their body size and not necessarily the largest nest available (Kvarnemo 1995). When contestants compete for shelters or nests, sizeassortative resource preferences occur (Kvarnemo 1995; Bolton et al. 2013). Consequently, similar-sized contestants compete for resources that are most suitable for their body size (e.g., Kvarnemo 1995; Jennions and Backwell 1996; Morrell et al. 2005).

\section{Combination of contestants' handedness}

Although the handedness of males is close to a 50:50 ratio in most fiddler crab species (Zeil et al. 2006; Backwell et al. 2007), and fights against same- and opposite-handed opponents occur in similar proportions (Pratt et al. 2003), the present results revealed that original and regenerated males preferred same- and opposite-handed contestants, respectively. This suggests that males may be able to discriminate the handedness of their opponent and use that knowledge to modify their fighting tactics.

Lateralization of behavior (i.e., preference for one side of the organism) during agonistic interactions has been reported in many species (e.g., Robins et al. 1998; Arnott et al. 2011; Elwood et al. 2014). For example, convict cichlids (Amatitlania nigrofasciata) present the right side of their body, which may facilitate assessment of their fighting ability (Arnott et al. 2011). Similarly, it might be easier for fiddler crabs to assess their opponent's strength when it is of the same-handedness (Hyatt and Salmon 1978; Backwell et al. 2007), especially when the claws of two contestants are interlocked. Therefore, the bluffing tactics used by regenerated males may be more obvious in same-handed fights. Before males engage in the interlock stage of the fight, the contestants often align their claws. It may be easier for opposite-handed contestants to accurately assess each other's claw length in such situations (Jennions and Backwell 1996; Backwell et al. 2007). Aligning claws does not incur any cost to regenerated males because the weapon size of regenerated males relative to their carapace width is similar to that of the original males (Fig. 1).

\section{Residency of the contestants}

While fights between resident males are rare in U. pugilator and Uca pugnax (Hyatt and Salmon 1978; Pratt et al. 2003), we found that $64.8 \%$ (79/122) of the fights occurred between resident males in $U$. lactea. This suggests that many of these fights result from border disputes between resident males. Alternatively, dedicated clawwaving displays used in burrow guarding may have prevented many of the fights between residents and intruders. Muramatsu (2011a, b) previously showed that $U$. lactea resident males performed different types of claw-waving display when they faced residents and intruders. In most cases, resident males were able to deter intruders by performing rapid vertical waving; therefore, fights between a resident and an intruder were commonly prevented before they initiated physical contact. 


\section{Fighting stages}

Animal conflicts often consist of several discrete stages, and the risk level increases as the contest moves through the sequence of stages (reviewed in Maynard Smith and Harper 2003). Fights between U. lactea males consisted of contact, interlock, and fling stages, and the risk of injury increased in this order. The differences in body and weapon sizes between two contestants were larger during the contact stage but smaller during the interlock or fling stages, suggesting that males proceeded to the interlock stage only when there was no apparent asymmetry in the contestants' fighting abilities. Consequently, the majority (58/110) of the fights were settled without escalating to more risky stages. These results are consistent with the sequential assessment model (Enquist et al. 1990); however, Taylor and Elwood (2003) reported that similar results might also be obtained through the pure self-assessment or cumulative assessment models (reviewed in Arnott and Elwood 2009).

The risk of fight escalation is more serious for males with regenerated claws because their weapon is more fragile than the original one. Indeed, our results showed that fights that escalated to the fling stage were considerably less frequent when one contestant had a regenerated claw, suggesting that most regenerated males surrendered when the contest escalated to the interlock stage. These results are consistent with our hypothesis that regenerated males would surrender when the fight escalates. Callander et al. (2012) reported that regenerated $U$. annulipes males fight harder during the mating period to compensate for the physical disadvantage of having a less-robust claw. Uca lactea have mating and non-mating periods during the breeding season (Yamaguchi 2001; Muramatsu 2010b); however, we did not discriminate between mating and non-mating periods in the present study.

Our results also showed that fights between resident males tended to terminate at early stages. This observation is consistent with the "dear enemy" phenomenon (sensu Fisher 1954), a term referring to the observation that residents of territorial animals respond less aggressively to neighboring residents than to strangers. A similar phenomenon has been reported in many taxa (listed in Temeles 1994), including other Uca species, such as U. pugilator (Pratt and McLain 2006).

\section{Factors affecting the fight outcome}

In fiddler crabs, several studies have shown the effects of carapace width (Pratt et al. 2003; Pratt and McLain 2006), claw length (Jennions and Backwell 1996), or both (Jaroensutasinee and Jaroensutasinee 2003; Jaroensutasinee and Tantichodok 2003; Morrell et al. 2005) on the probability of winning in male-male fights. Our results also showed that both carapace width and claw length affected the probability of success and that longer major claws contributed more to the probability of winning.

The best model obtained from the glmer analyses contained "claw length difference" and "combination of claw types" as the explanatory variables. The coefficients of each explanatory variable indicate that males with longer claws tended to win fights more frequently and that original males were more likely to defeat regenerated males. According to this model, regenerated males win over original males in $29.1 \%$ of the size-matched fights, and the probability of winning increases to $50.0 \%$ when they have a 2.13 -mm-longer claw. Thus, the handicap of having a regenerated claw is compensated for by the possession of a claw that is longer than that of the opponent.

The other three explanatory variables (combination of residency, combination of handedness, and fighting stage) produced a weaker fit and were dropped by the 
process of model selection, despite the influence of these factors during the choice of an opponent. The effects of these three factors may have been masked by the process involved in choosing an opponent; that is, contestants may have engaged in or escalated fights only when they had a chance of winning. These results emphasize the importance of investigating pre-fight tactics, such as the choice of opponent.

\section{Conclusions}

The present results confirmed our five hypotheses. The relationships between claw length and carapace width were similar between the original and regenerated males. Males seemed to be unable to discriminate original claws from regenerated claws, because males with a regenerated claw were not selectively challenged by other males. Regenerated males chose smaller and opposite-handed opponents and surrendered when the fight escalated beyond the contact stage. These results are consistent with our hypothesis that regenerated males would rely on bluffing tactics. In contrast, original males chose same-handed opponents and persisted in the contest even when their opponent was larger, and they often defeated regenerated males equipped with a longer claw. These results support our hypothesis that original males employ counter-bluff tactics. Taken together, these results suggest that $U$. lactea males adopt different tactics and switch their fighting tactics when they lose and regenerate their major claw.

\section{Acknowledgments}

We thank Professor S. Kohshima at Kyoto University for critical comments on this study. We also thank Y. Endo and H. Sakuragi at Kyoto University for editing the manuscript's English. This research was financially supported in part by JSPS Coreto-Core Program, A. Advanced Research Networks "Tropical Biodiversity Conservation," Wildlife Research Center, Kyoto University.

\section{Ethical approval}

All procedures performed in this study involving animals were conducted in accordance with the ethical standards of the Guidelines for Animal Studies in the Wild issued by the Wildlife Research Center of Kyoto University. This article does not contain any study with human participants.

\section{References}

Adams ES, Caldwell RL (1990) Deceptive communication in asymmetric fights of the stomatopod crustacean Gonodactylus bredini. Anim Behav 39:706-716

Angilletta MJ Jr, Wilson RS (2012) Cryptic asymmetry: unreliable signals mask asymmetric performance of crayfish weapons. Biol Lett 8:551-553

Arnott G, Elwood RW (2009) Assessment of fighting ability in animal contests. Anim Behav 77:991-1004

Arnott G, Ashton C, Elwood RW (2011) Lateralization of lateral displays in convict cichlids. Biol Lett 7:683-685 
Backwell PRY, Christy JH, Telford SR, Jennions MD, Passmore NI (2000) Dishonest signalling in a fiddler crab. P Roy Soc Lond B Bio 267:719-724

Backwell PRY, Matsumasa M, Double M, Roberts A, Murai M, Keogh JS, Jennions MD (2007) What are the consequences of being left-clawed in a predominantly rightclawed fiddler crab? P Roy Soc Lond B Bio 274: 2723-2729

Bolton J, Backwell PRY, Jennions MD. (2013) Density dependence and fighting in species with indeterminate growth: a test in a fiddler crab. Anim Behav 85:1367-1376

Bywater CL, Angilletta MJ, Wilson RS (2008) Weapon size is a reliable indicator of strength and social dominance in female slender crayfish (Cherax dispar). Funct Ecol 22:311-316

Bywater CL, White CR, Wilson RS (2014) Metabolic incentives for dishonest signals of strength in the fiddler crab Uca vomeris. J Exp Biol 217:2848-2850

Callander S, Bolton J, Jennions MD, Backwell PRY (2012) A farewell to arms: males with regenerated claws fight harder over resources. Anim Behav 84:619-622

Callander S, Kahn AT, Maricic T, Jennions MD, Backwell PRY (2013) Weapons or mating signals? Claw shape and mate choice in a fiddler crab. Behav Ecol Sociobiol 67:1163-1167

Candolin U (2000) Increased signalling effort when survival prospects decrease: male-male competition ensures honesty. Anim Behav 60:417-422

Elwood RW, Arnott G (2012) Understanding how animals fight with Lloyd Morgan's canon. Anim Behav 84:1095-1102

Elwood RW, Pothanikat RME, Briffa M (2006) Honest and dishonest displays, motivational state and subsequent decisions in hermit crab shell fights. Anim Behav 72:853-859

Elwood RW, Stoilova V, McDonnell A, Earley RL, Arnott G (2014) Do mirrors reflect reality in agonistic encounters? A test of mutual cooperation in displays. Anim Behav 97:63-67

Enquist M, Leimar O, Ljungberg T, Mallner Y, Segerdahl N (1990) A test of the sequential assessment game: fighting in the cichlid fish Nannacara anomala. Anim Behav 40:1-14

Fisher J (1954) Evolution and bird sociality. In: Huxley J, Hardy A, Ford E (eds) Evolution as a process. London, Allen and Unwin. 84:71-83

Games PA, Howell JF (1976) Pairwise multiple comparison procedures with unequal n's and/or variances: A Monte Carlo study. J Educ Stat 1:113-125

Goncalves D, Matos R, Fagundes T, Oliveira R (2005) Bourgeois males of the peacock blenny, Salaria pavo, discriminate female mimics from females? Ethology 


\section{$111: 559-572$}

Gross MR (1996) Alternative reproductive strategies and tactics: diversity within sexes. Trends Ecol Evol 11:92-98

Hyatt GW, Salmon M (1978) Combat in the fiddler crabs Uca pugilator and $U$. pugnax: a quantitative analysis. Behaviour 65:182-211

Jaroensutasinee M, Jaroensutasinee K (2003) Male body size influences female choice and male-male competition in the fiddler crab, Uca paradussumieri Bott, 1973 (Decapoda, Brachyura, Ocypodidae). Crustaceana 76:177-186

Jaroensutasinee M, Tantichodok P (2003) Effects of size and residency on fighting outcomes in the fiddler crab, Uca vocans hesperiae (Decapoda, Brachyura, Ocypodidae). Crustaceana 75:1107-1117

Jennions MD, Backwell PRY (1996) Residency and size affect fight duration and outcome in the fiddler crab Uca annulipes. Biol J Linn Soc 57:293-306

Johnstone RA, Grafen A (1993) Dishonesty and the handicap principle. Anim Behav 46:759-764

Krupa JJ (1989) Alternative mating tactics in the Great Plains toad. Anim Behav 37:1035-1043

Kvarnemo C (1995) Size-assortative nest choice in the absence of competition in males of the sand goby, Pomatoschistus minutus. Environ Biol of Fish 43:233-239

Lailvaux SP, Reaney LT, Backwell PRY (2009) Dishonest signalling of fighting ability and multiple performance traits in the fiddler crab Uca mjoebergi. Funct Ecol 23:359-366

Luttbeg B (2004) Female mate assessment and choice behavior affect the frequency of alternative male mating tactics. Behav Ecol 15:239-247

Maynard Smith J, Harper D (2003) Animal signals. Oxford University Press. Oxford

McLain DK, McBrayer LD, Pratt AE, Moore S (2010) Performance capacity of fiddler crab males with regenerated versus original claws and success by claw type in territorial contests. Ethol Ecol Evol 22:37-49

Mills SC, Reynolds JD (2003) Operational sex ratio and alternative reproductive behaviours in the European bitterling, Rhodeus sericeus. Behav Ecol Sociobiol 54:98104

Morrell LJ, Backwell PRY, Metcalfe NB (2005) Fighting in fiddler crabs Uca mjoebergi: what determines duration? Anim Behav 70:653-662

Munoz A, Aparicio JM, Bonal R (2008) Male barn swallows use different resource allocation rules to produce ornamental tail feathers. Behav Ecol Sociobiol 19:404-409 
Muramatsu D (2010a) Temporary loss of a sexual signal (claw loss) affects the frequency of sand structure construction in the fiddler crab, Uca lactea. Ethol Ecol Evol 22:87-93

Muramatsu D (2010b) Sand structure construction in Uca lactea (De Haan, 1835) is related to tidal cycle but not to male or female densities. Crustaceana 83:29-37

Muramatsu D (2011a) For whom the male waves: four types of claw-waving display and their audiences in the fiddler crab, Uca lactea. J Ethol 29:3-8

Muramatsu D (2011b) The function of the four types of waving display in Uca lactea: Effects of audience, sand structure, and body size. Ethology 117:408-415

Pope DS (2005) Waving in a crowd: fiddler crabs signal in networks. In: McGregor PK (ed.) Animal Communication Networks. Cambridge University Press, Cambridge

Pratt AE, McLain DK (2002) Antisymmetry in male fiddler crabs and the decision to feed or breed. Funct Ecol 16 (1):89-98

Pratt AE, McLain DK (2006) How dear is my enemy: Intruder-resident and residentresident encounters in male sand fiddler crabs (Uca pugilator). Behaviour 143:597617

Pratt AE, McLain DK, Lathrop GR (2003) The assessment game in sand fiddler crab contests for breeding burrows. Anim Behav 65:945-955

Raihani G, Serrano-Meneses MA, Cordoba-Aguilar A (2008) Male mating tactics in the American rubyspot damselfly: territoriality, nonterritoriality and switching behavior. Anim Behav 75:1851-1860

R Core Team (2015) R: A language and environment for statistical computing. R Foundation for Statistical Computing, Vienna, Austria. http://www.R-project.org. Accessed 20 September 2015

Reaney LT, Milner RNC, Detto T, Backwell PRY (2008) The effects of claw regeneration on territory ownership and mating success in the fiddler crab Uca mjoebergi. Anim Behav 75:1473-1478

Robins A, Lippolis G, Bisazza A, Vallortigara G, Rogers LJ (1998) Lateralized agonistic responses and hindlimb use in toads. Anim Behav 56:875-881

Rosenberg MS (2001) The systematics and taxonomy of fiddler crabs: a phylogeny of the genus Uca. J Crust Biol 21:839-869.

Sato T, Hirose M, Taborsky M, Kimura S (2004) Size-dependent male alternative reproductive tactics in the shell-brooding cichlid fish Lamprologus callipterus in Lake Tanganyika. Ethology 110:49-62

Searcy WA, Nowicki S (2005) The Evolution of animal communication: Reliability 
and deception in signaling systems. Princeton University Press, New Jersey

Semple S, McComb K (1996) Behavioural deception. Trends Ecol Evol 11:434-437

Shine R, Langkilde T, Mason RT (2003) The opportunistic seprent: Male garter snakes adjust courtship tactics to mating opportunities. Behaviour 140:1509-1526

Steger R, Caldwell RL (1983) Intraspecific deception by bluffing a defense strategy of newly molted stomatopods (Arthropoda, Crustacea). Science 221:558-560

Stuart-Fox D (2005) Deception and the origin of honest signals. Trends Ecol Evol 20:521-523

Taylor PW, Elwood RW (2003) The mismeasure of animal contests. Anim Behav 65:1195-1202

Temeles EJ (1994) The role of neighbors in territorial systems; when are they 'dear enemies'? Anim Behav 47:339-350

Tsubaki Y, Ono T. 1986. Competition for territorial sites and alternative mating tactics in the dragonfly, Nannophya pygmaea Rambur (Odonata: Libellulidae). Behaviour 97:234-252

Walter GM, van Uitregt VO, Wilson RS (2011) Social control of unreliable signals of strength in male but not female crayfish, Cherax destructor. J Exp Biol 214:32943299

Wilson RS, Angilletta MJ, James RS, Navas C, Seebacher F (2007) Dishonest signals of strength in male slender crayfish (Cherax dispar) during agonistic encounters. Am Nat 170:284-291

Yamaguchi T (1973) Asymmetry and dimorphism of chelipeds in the fiddler crab, Uca lactea De Haan. Zool Mag 82:154-158

Yamaguchi T (2001) The breeding period of the fiddler crab, Uca lactea (Decapoda, Brachyura, Ocypodidae). Crustaceana 74:285-293

Zeil J, Hemmi JM, Backwell PRY (2006) Fiddler crabs. Curr Biol 16:40-41 


\section{Figure legends}

Fig. 1 Correlation between carapace width and claw length of original and regenerated males. The slope for original males is represented by the dashed line ( $Y=$ $\left.2.407 X-11.774, R_{\text {adj }}^{2}=0.955\right)$, and the solid line denotes the slope for regenerated males $\left(Y=2.474 X-12.908, R^{2}\right.$ adj $\left.=0.635\right)$.

Fig. 2 Size differences between the two contestants at each fighting stage. (a) Carapace width differences between pairs of contestants. (b) Claw length differences between pairs of contestants. Box plots labeled with different letters differ significantly (Games-Howell test; $P<0.05$ ). Values represent the median (horizontal line), 25th and 75th percentiles (box), and maximum and minimum observed values (range bars).

Fig. 3 Relationship between claw type and fighting stage. "Original vs. Original" indicates fights between original males, and "Original vs. Regenerated" refers to fights between original and regenerated males.

Fig. 4 Relationship between burrow residency and fighting stage. "Resident vs. Resident" indicates fights between males who both had a burrow, and "Resident vs. Intruder" refers to fights in which only one male had a burrow.

Fig. 5 Carapace widths of winning and losing males. The dashed line indicates equal carapace widths for both contestants. When a point is located below the dashed line, this means the winner was larger than the loser.

Fig. 6 Claw lengths of winning and losing males. The dashed line indicates equal claw lengths for both contestants. When a point is located below the dashed line, this means the winner had a longer claw than its opponent.

Fig. 7 Probabilities of winning a contest, estimated by the best model (Table 6). Note that the word pairs indicate the claw type of the focal and opponent males, respectively.

ESM_1.mpg Examples of same-handed and opposite-handed fights. Claws can be tightly clamped in same-handed fights, but it appears to be mechanically challenging to interlock claws in opposite-handed fights.

ESM_2.mpg Example of a fight involving a regenerated male trying to escape from a claw interlock.

ESM_3.mpg Example of a fight in which the largest claw difference $(7.35 \mathrm{~mm})$ was observed and the fight was won by the male with the shorter (original) claw. 


\section{Tables}

Table 1: Description of the three stages in contests that escalate to physical contact (i.e., fights)

\begin{tabular}{ll}
\hline Stage & Description \\
\hline Contact & $\begin{array}{l}\text { Major claws of the two contestants come in contact with each other } \\
\text { but without interlock. Shoving may or may not occur. There is little } \\
\text { or no risk of injury. }\end{array}$ \\
Interlock & $\begin{array}{l}\text { Major claws of the two contestants are intercrossed, and at least one } \\
\text { contestant pinches the opponent's claw. (Generally, both contestants } \\
\text { tightly clamp each other's claw.) Vigorous shoving occurs, and the } \\
\text { claws often make a squeaking noise. There is significant risk of } \\
\text { injury. } \\
\text { Fling }\end{array}$ \\
& $\begin{array}{l}\text { One contestant lifts the opponent from the substrate or even flips his } \\
\text { opponent. There is a high risk of injury and loss of burrow. }\end{array}$ \\
\hline
\end{tabular}

Table 2: Morphological comparison between original and regenerated males

\begin{tabular}{|c|c|c|c|}
\hline & Original male & $\begin{array}{l}\text { Regenerated } \\
\text { male }\end{array}$ & Statistical result $(t$-test $)$ \\
\hline $\begin{array}{l}\text { Carapace width } \\
(\mathrm{mm})\end{array}$ & $12.85 \pm 1.59$ & $13.48 \pm 1.26$ & $\begin{array}{l}t=-1.972, \mathrm{df}=137, P= \\
0.051\end{array}$ \\
\hline $\begin{array}{l}\text { Major claw } \\
\text { length }(\mathrm{mm})\end{array}$ & $19.11 \pm 3.90$ & $20.43 \pm 3.87$ & $\begin{array}{l}t=-1.625, \mathrm{df}=135, P= \\
0.107\end{array}$ \\
\hline $\begin{array}{l}\text { Minor claw } \\
\text { length }(\mathrm{mm})\end{array}$ & $5.28 \pm 0.71$ & $5.48 \pm 0.58$ & $\begin{array}{l}t=-1.466, \mathrm{df}=137, P= \\
0.145\end{array}$ \\
\hline
\end{tabular}

All measurements are mean \pm SD.

Table 3: Differences in carapace width and major claw length in contests between original and regenerated males

Original male $\quad$ Regenerated $\quad$ Statistical result (paired $t$ male test)

\begin{tabular}{llll}
\hline $\begin{array}{l}\text { Carapace width } \\
\text { (mm) }\end{array}$ & $12.96 \pm 1.48$ & $13.51 \pm 1.22$ & $\begin{array}{l}t=-2.863, \mathrm{df}=41, P< \\
0.01\end{array}$ \\
Major claw & $19.37 \pm 3.38$ & $20.87 \pm 4.24$ & $\begin{array}{l}t=-2.694, \mathrm{df}=41, P< \\
0.05\end{array}$ \\
length (mm) & & & \\
\hline
\end{tabular}

All measurements are mean \pm SD. 
Table 4: Values of Akaike's information criterion (AIC), ranked in increasing order, calculated from general linear models for the correlation between carapace width and claw length

\begin{tabular}{lll}
\hline Rank & Model term(s) & AIC \\
\hline 1 & Carapace width & 460.51 \\
2 & Carapace width, Claw type & 461.74 \\
3 & Carapace width, Claw type, Carapace width $\times$ Claw type & 463.63 \\
4 & Square of carapace width & 471.03 \\
5 & Square of carapace width, Claw type & 472.76 \\
6 & Square of carapace width, Claw type, Square of carapace width $\times$ & 474.76 \\
& Claw type & 765.12 \\
7 & Claw type & 765.78 \\
\hline
\end{tabular}

Table 5: Values of Akaike's information criterion (AIC), ranked in increasing order, for the top $\mathbf{1 0}$ models in the glmer analysis for predicting the probability of winning a contest. "Contest stage" is defined in Table 1.

\begin{tabular}{|c|c|c|}
\hline Rank & Model term(s) & AIC \\
\hline 1 & Claw length difference, Combination of claw types & 47.1 \\
\hline 2 & Claw length difference, Combination of handedness & 49.6 \\
\hline 3 & $\begin{array}{l}\text { Claw length difference, Combination of claw types, Combination } \\
\text { of handedness }\end{array}$ & 49.6 \\
\hline 4 & Claw length difference, Contest stage & 50.1 \\
\hline 5 & $\begin{array}{l}\text { Claw length difference, Combination of claw types, Contest } \\
\text { stage }\end{array}$ & 50.1 \\
\hline 6 & $\begin{array}{l}\text { Claw length difference, Combination of claw types, Combination } \\
\text { of residency }\end{array}$ & 50.7 \\
\hline 7 & $\begin{array}{l}\text { Claw length difference, Combination of handedness, Contest } \\
\text { stage }\end{array}$ & 52.6 \\
\hline 8 & $\begin{array}{l}\text { Claw length difference, Combination of claw types, Combination } \\
\text { of handedness, Contest stage }\end{array}$ & 52.6 \\
\hline 9 & Claw length difference, Combination of residency, Contest stage & 53.2 \\
\hline 10 & $\begin{array}{l}\text { Claw length difference, Combination of claw types, Combination } \\
\text { of residency, Contest stage }\end{array}$ & 53.2 \\
\hline
\end{tabular}

Note that claw length difference and carapace width difference were not used within the same model as these factors were strongly correlated (see Fig. 1). 
Table 6: Parameter estimates for the best model in Table 5

\begin{tabular}{lll}
\hline Model term & Coefficient & SE \\
\hline Intercept & 1.2705 & 0.7040 \\
Claw length difference & 0.4169 & 0.1448 \\
$\begin{array}{l}\text { Combination of claw types (regenerated versus } \\
\text { original) }\end{array}$ & -2.1598 & 1.0692 \\
\hline
\end{tabular}

Note that the estimates for claw type were calculated based on the fights in which the focal male had an original claw and the opponent male had a regenerated claw, i.e., the parameter estimate of "Combination of claw types (original versus regenerated)" was adjusted to zero. 


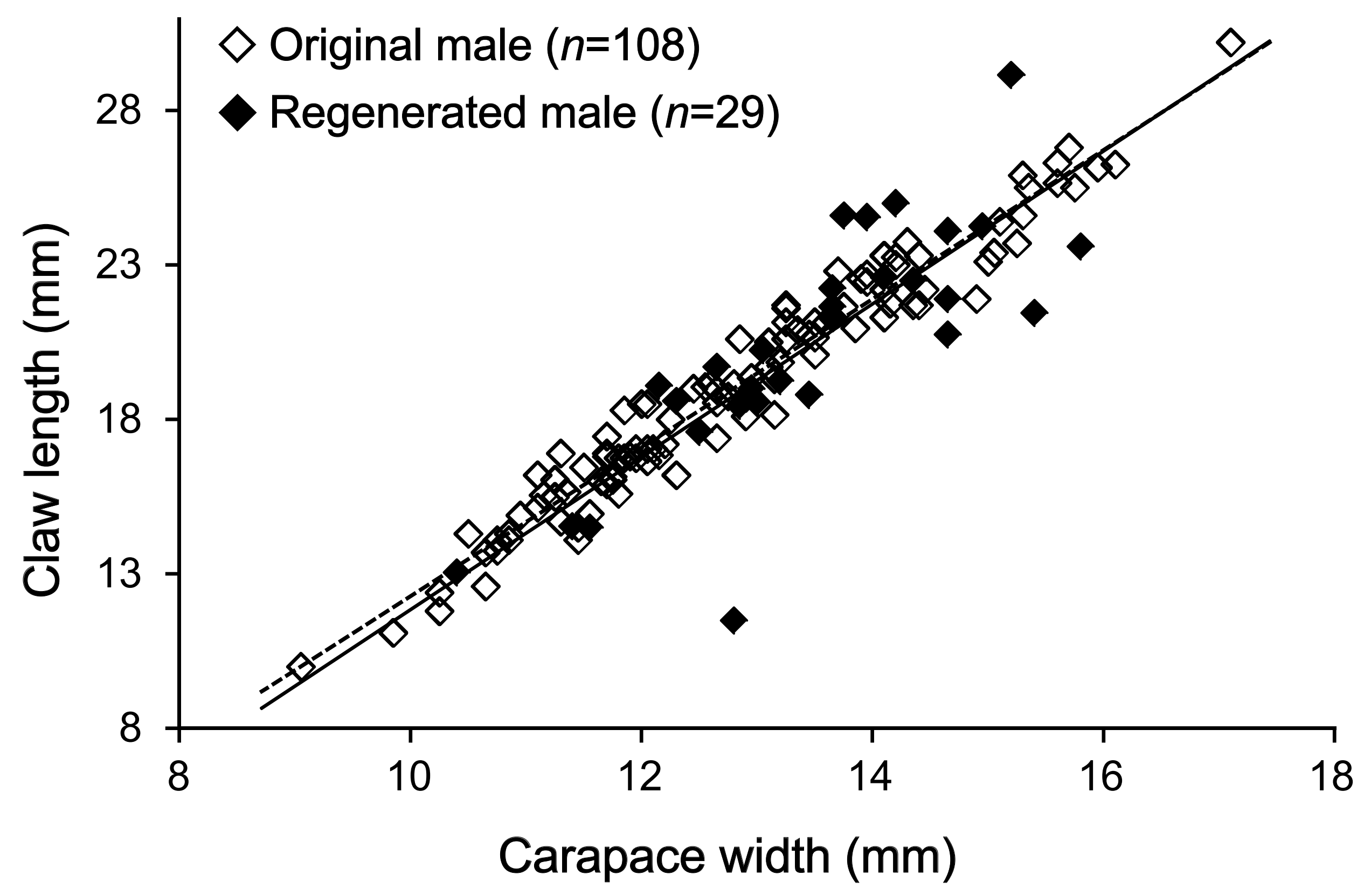

Fig. 1 

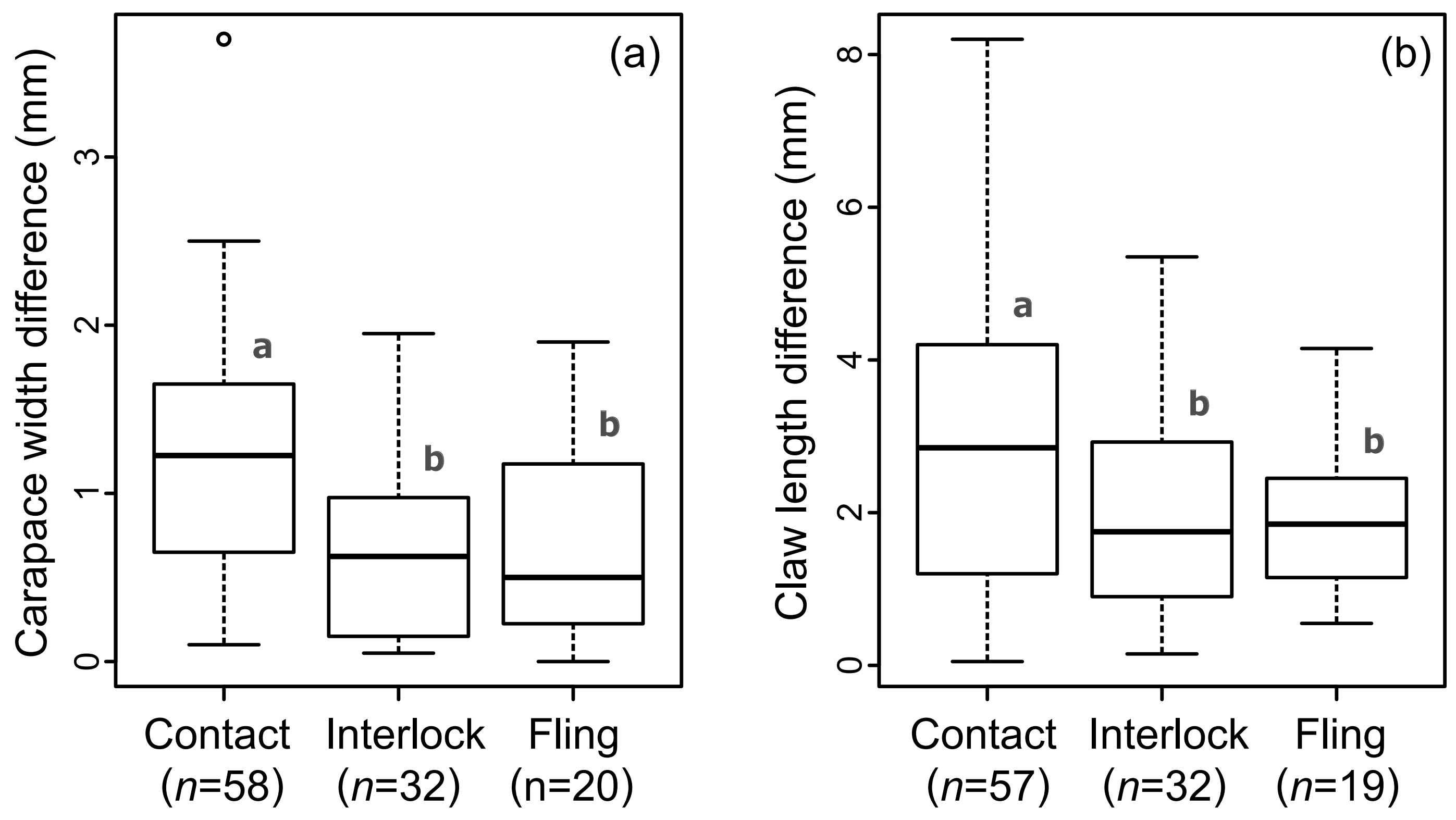

Fig. 2 


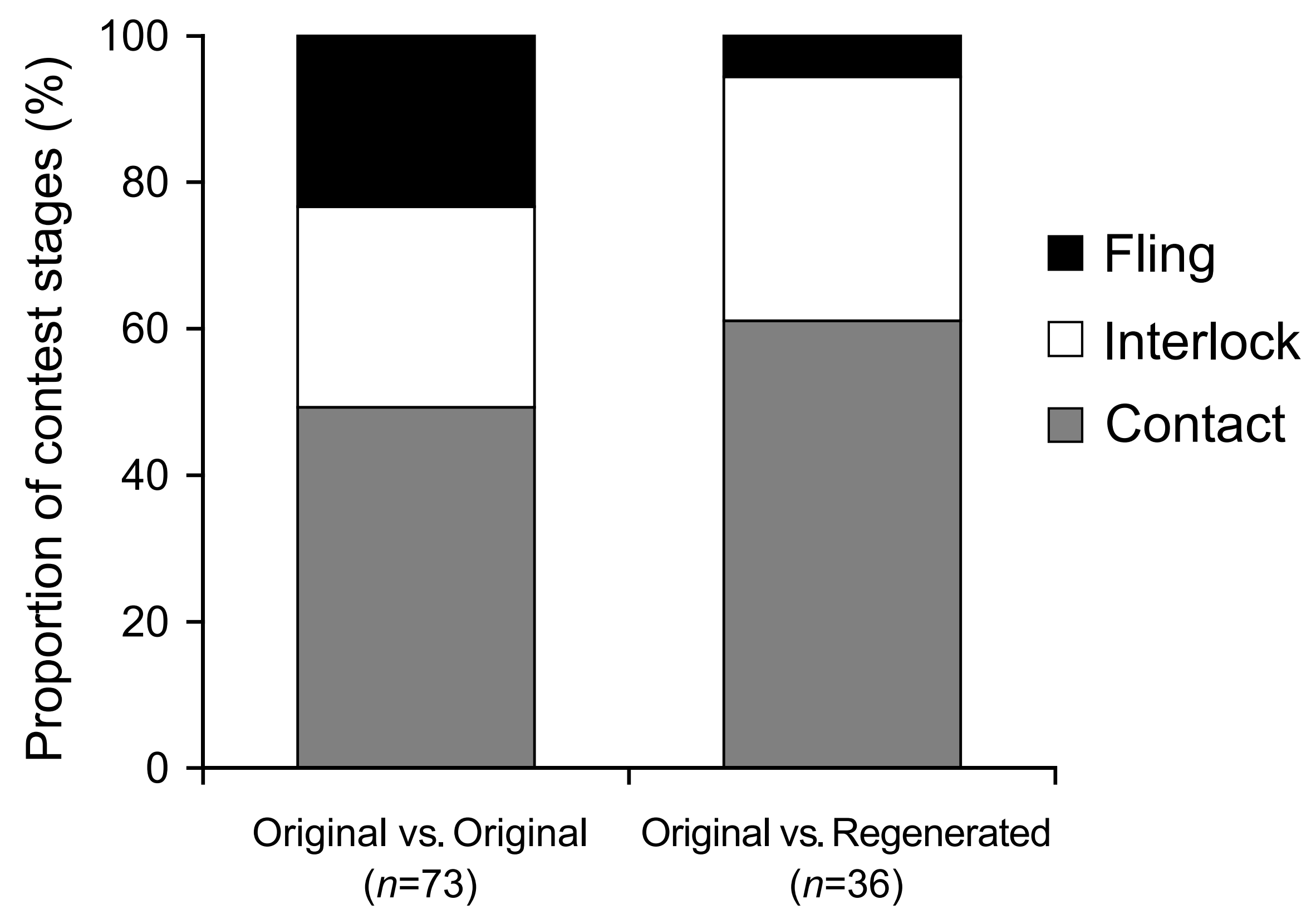

Fig. 3 


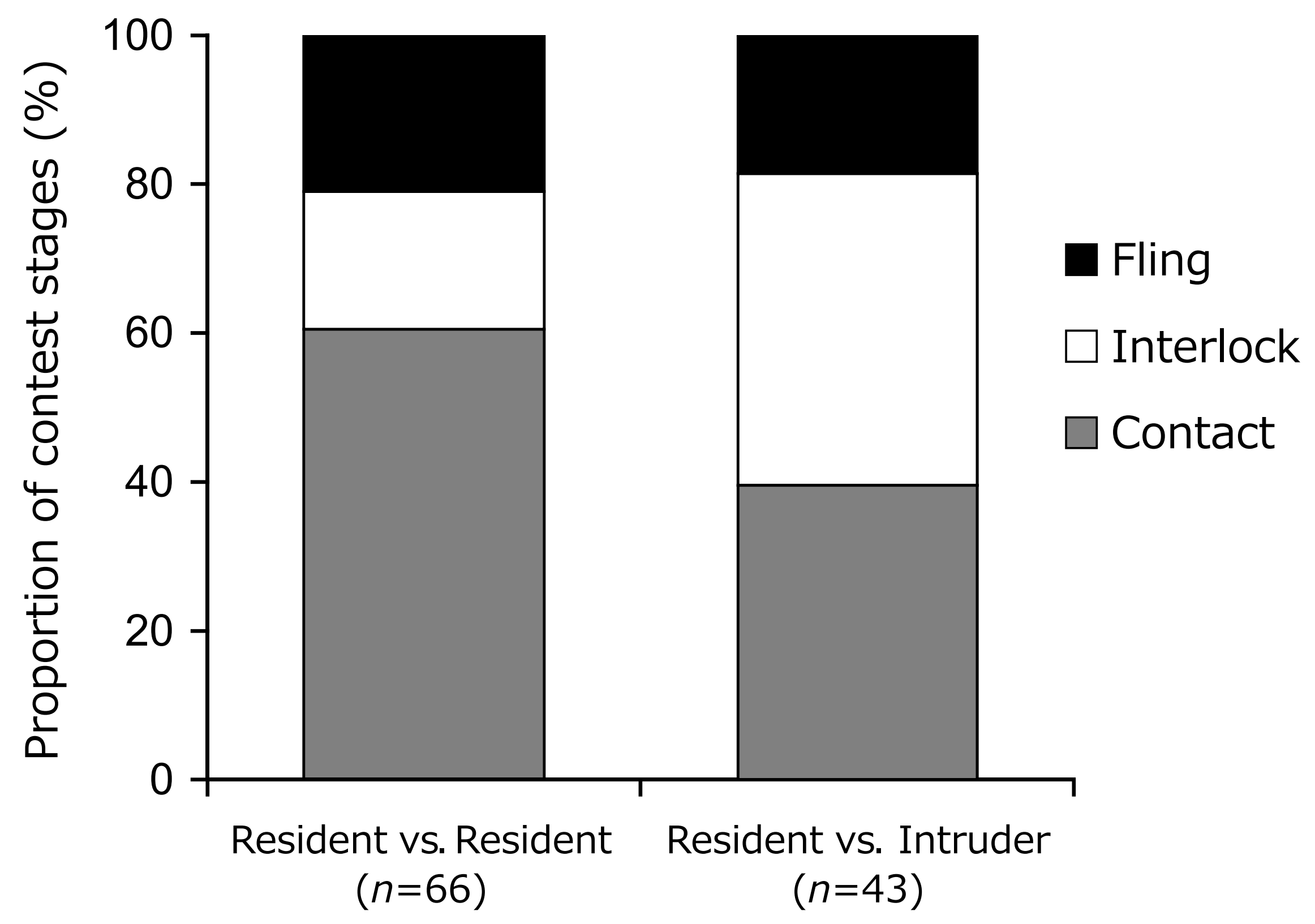

Fig. 4 


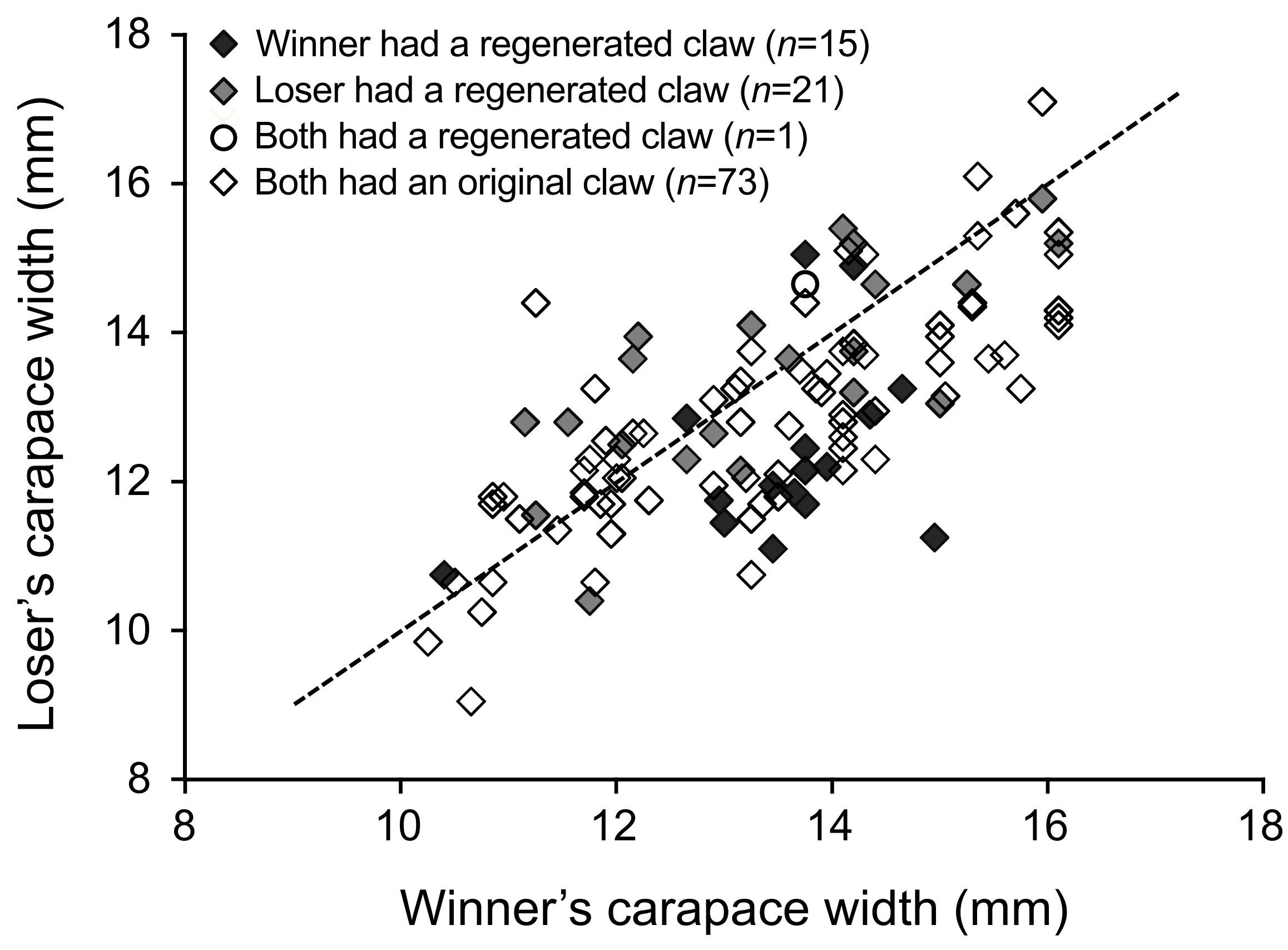

Fig. 5 


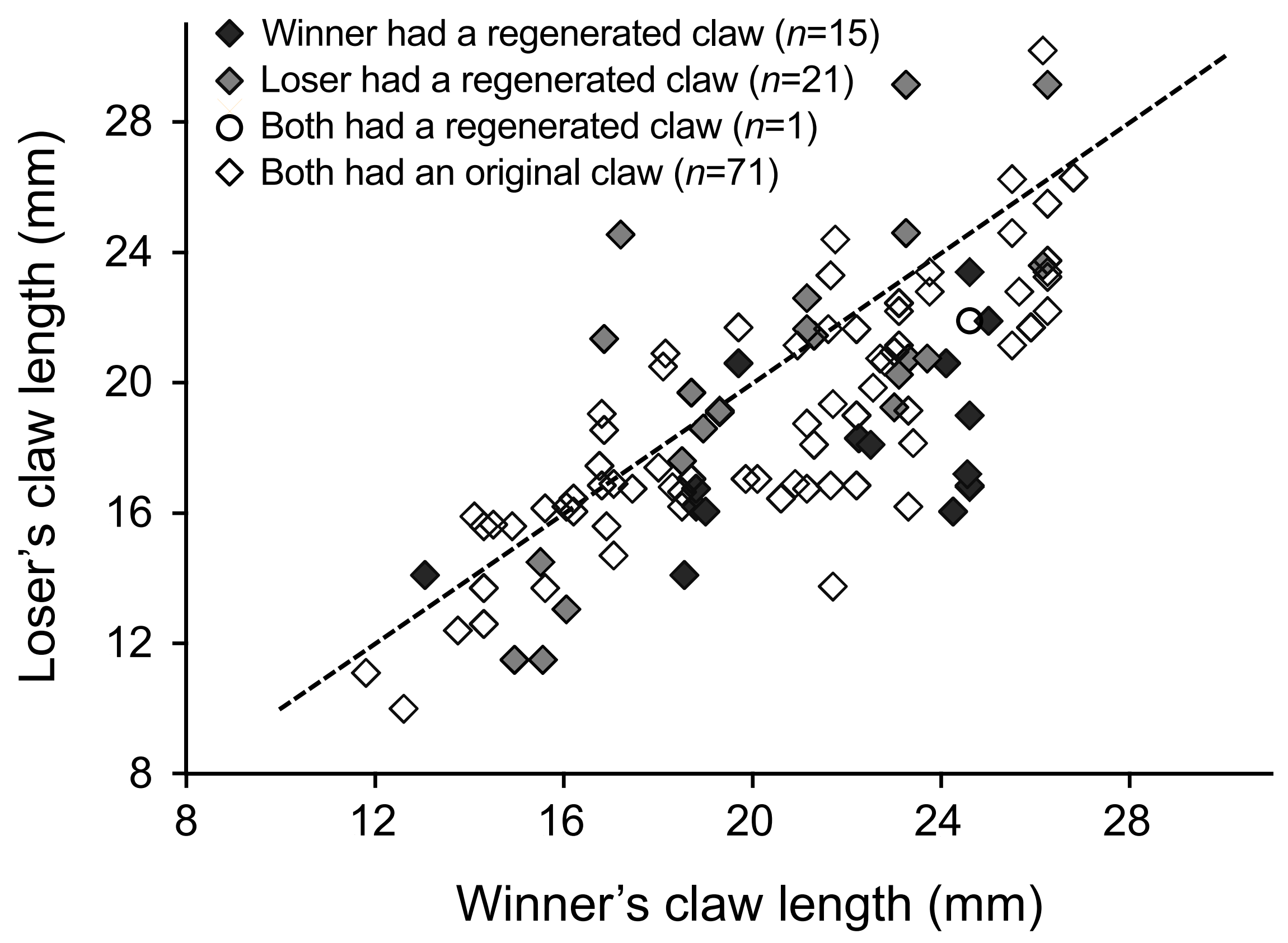

Fig. 6 


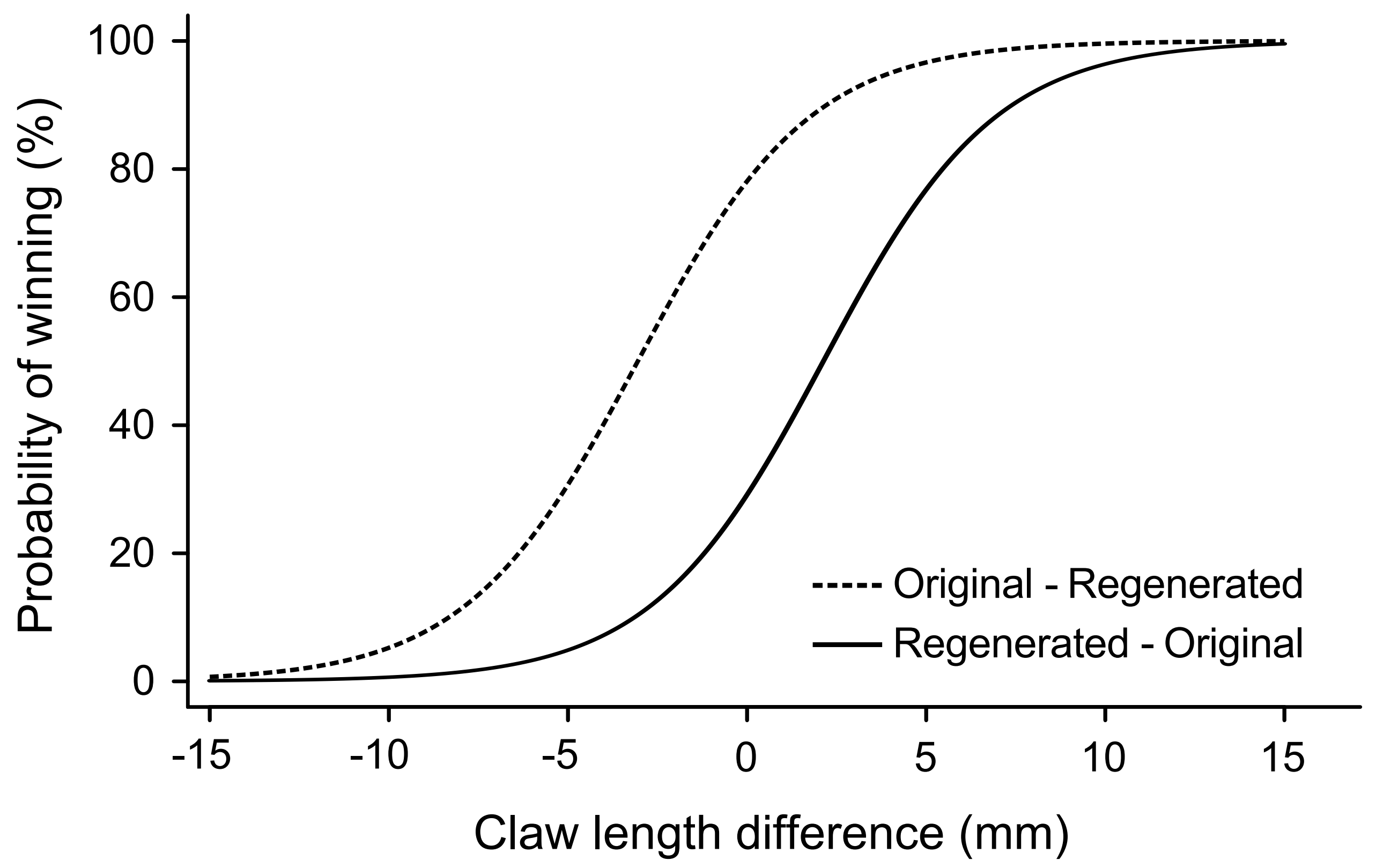

Fig. 7 